\title{
Special Issue to Mark the Career and the Retirement of Professor Sun Bok Lee
}

\author{
Sung Kuk Lee and Keehoon Won \\ Special Issue Guest Editors
}

(C) The Korean Society for Biotechnology and Bioengineering and Springer 2019

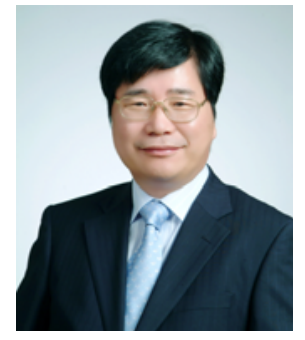

Prof. Sun Bok Lee
This special issue is published to honor the retirement of Prof. Sun Bok Lee who served as the founding Executive Editor of Biotechnology and Bioprocess Engineering during 1996-2008. Many researchers in various fields of biotechnology have willingly contributed to this special issue to express their respect for him.

Prof. Lee graduated from Seoul National University in 1976 with a BSc in Chemical Engineering and then received an MSc in Biological Engineering in 1978 followed by a $\mathrm{PhD}$ degree in Biochemical Engineering in 1981 from Korea Advanced Institute of Science \& Technology (KAIST). His $\mathrm{PhD}$ thesis focused on the enzymatic hydrolysis of cellulose, and he was advised by Prof. Dewey D. Y. Ryu, who was a professor at Massachusetts Institute of Technology (MIT) and contributed significantly as a founding faculty member for the development of biotechnology curricular and research programs at KAIST; he is currently an emeritus professor at the University of California, Davis. Prof. Lee's relevant research papers are cited in the most widely used biochemical engineering textbooks, Biochemical Engineering Fundamentals (2nd ed., McGraw-Hill, New York, 1986) by James E. Bailey

Sung Kuk Lee

Department of Chemical Engineering, Ulsan National Institute of Science and Technology (UNIST), Ulsan 44919, Korea

Tel: +82-52-217-2514; Fax: +82-52-217-3009

E-mail: sklee@unist.ac.kr

Keehoon Won

Department of Chemical and Biochemical Engineering, Dongguk University-Seoul, Seoul 04620, Korea

Tel: +82-2-2260-8922; Fax: +82-2-2268-8729

E-mail:keehoon@dongguk.edu and David F. Ollis, and Biochemical Engineering (Prentice Hall, Englewood Cliffs, 1992) by James M. Lee.

After receiving his $\mathrm{PhD}$, he began his new research journey as a research fellow for two years in Prof. J. E. Bailey's laboratory in the Department of Chemical Engineering at California Institute of Technology (CALTECH) in the United States. His highlighted research contribution at CALTECH was theoretical modeling of gene expression in cells, and other key findings were also listed in Biochemical Engineering Fundamentals. In addition, his article entitled 'Analysis of growth rate effects on productivity of recombinant Escherichia coli populations using molecular mechanism models' was selected as one of the 20 most influential papers among those published from 1959 to 1999 in Biotechnology \& Bioengineering, and included in the special issue to celebrate the $40^{\text {th }}$ anniversary of the journal in March of 2000 .

After returning to Korea in 1983, he joined the Department of Chemical Engineering at KAIST for two and a half years. In 1986, he moved to the Genetic Engineering Research Institute and participated in Korea's first genetic engineering research project on the production of recombinant human interleukin-2. At that time, we lacked any experiences in developing genetic engineering products, his team succeeded in not only generating the recombinant protein but also performing its clinical trials for the first time in Korea. This paved the way for the establishment of genetic engineering technology in Korea. In recognition of his pioneer achievement, the Excellent Research Prize was awarded by the Ministry of Science and Technology in 1988.

He joined the Department of Chemical Engineering at Pohang University of Science and Technology (POSTECH) as a faculty member in 1989, and his research since has been focused on enzymes from extremophiles with keen 
interests on their industrial applications and developments. In 1995, he was appointed as an Editorial Board Member of Journal of Molecular Catalysis B: Enzymatic, which is an esteemed international journal of Elsevier on the applications of isolated enzymes and whole cells as catalysts. Now, he is applying his enormous research experience in deciphering the marine microorganisms for their versatile applications. Marine microbiology is providing many new solutions to industry, including novel environment-friendly chemical processes and industrially attractive extremozymes which are active in low temperature and high salt conditions.

Prof. Lee's immense contributions to science have been reflected in his 142 published peer-reviewed research papers and 16 granted patents. He has also mentored a vibrant group of excellent researchers of about $50 \mathrm{PhD}$ and MSc students, who are now working actively in academia and various industries.

He has significantly contributed to the development and growth of the Korean Society for Biotechnology and Bioengineering (KSBB), serving as the President (2009) and Executive Editor of Biotechnology and Bioprocess
Engineering (1996-2008), which is an international scientific journal published by KSBB and Springer Nature. In addition, he served many other professional organizations with all his energy and passion for a long time, for example as President (1993-1996) of the Biocatalyst Research Society, as Chairman (1999-2000) of Biochemical Engineering Division, the Korean Institute of Chemical Engineering (KIChE), as Director (2006-2009) of Korea Science and Engineering Foundation, and as Director (2009-2013) of the Gyeongbuk Sea Grant Center. He has been also invited to serve as many advisory committee memberships and editorial board memberships of many government and research organizations.

$\mathrm{He}$ is the recipient of numerous honors, awards, and prizes including Isuapsis Grand Prize of Academic Achievements from KSBB, Yangjung Biochemical Engineering Award from KIChE, and Best Paper of the Year Award from Genetic Engineering Research Institute.

On behalf of all the authors of the Special Issue and the members of KSBB, we wish Professor Sun Bok Lee a happy retirement, good health, and many more years of scientific success.

Publisher's Note Springer Nature remains neutral with regard to jurisdictional claims in published maps and institutional affiliations. 